\title{
COVID-19 and Ozone
}

\author{
Necat Yılmaz' (D, Esin Eren' (1), Cemile Öz² (1) \\ 'Department of Medical Biochemistry, LC/MS-MS Laboratory, University of Health Sciences Antalya Training and Research Hospital, \\ Antalya, Turkey \\ 2Department of Medical Biochemistry, University of Health Sciences Antalya Training and Research Hospital, Antalya, Turkey
}

ORCID iDs of the authors: N.Y. 0000-0002-3865-9156; E.E. 0000-000I-9780-2437; C.Ö. 0000-000I-7835-7454.

Cite this article as: Yılmaz N, Eren E, Öz C. COVID-19 and Ozone. Cyprus J Med Sci 2020; 5(4): 365-72.

COVID-19 is characterized by an abnormal inflammatory response associated with endothelial dysfunction and microvascular complications. Unfortunately, no specific treatment for the disease and its life-threatening complications is available as of now. Ozone (O3) gas is a molecule consisting of three oxygen atoms in a dynamically unstable structure due to the presence of mesomeric states. Although $\mathrm{O} 3$ can have dangerous effects, it can have many therapeutic effects due to hormesis. The direct effect of ozone may be the direct inactivation of COVID-19, stimulation of oxygen metabolism, and activation of the immune system. Fortunately, COVID-19 contains sulfur-bound proteins that can be easily damaged through ozone oxidation. This structural content can be crucial to the antiviral effect because ozone can easily break down the double bonds in sulfur protein structures through a reaction called ozonolysis. Therefore, medical ozone can help reduce pneumonia, slow viral replication, regulate lung circulation and oxygenation, and prevent microvascular thrombosis. Ozone therapy can be considered as a cost-effective and easy-to-administer adjunct therapy while awaiting the development of a specific drug or vaccine for COVID-19. Furthermore, a growing number of studies have shown that ozone can be used as an adjuvant therapy for COVID-19.

Keywords: Ozone, COVID-19, SARS-CoV-2, ferritin, hormesis

\section{INTRODUCTION}

As of today, coronaviruses are still important human and animal pathogens. SARS-CoV-2 has been identified by the World Health Organization (WHO) as the cause of the COVID-19 pandemic that is still ongoing. In July 2020, when this article was written, about II million confirmed cases worldwide and unfortunately $>700,000$ deaths from COVID-I9 were reported. Taxonomically, COVID-19 has the genus Riboviria, which is a coronavirus related with severe acute respiratory syndrome, origin of Nidovirales, sub-origin Cornidovirineae, family Coronaviridae, and subfamily Orthocoronavirinae. Like many other coronaviruses, COVID-19 spreads through airborne droplets or through direct contact, from person to person or from surface to person $(1,2)$.

Because COVID-19 is a small +ssRNA virus, its average diameter varies but is between 60 and $140 \mathrm{~nm}$. The virus is very mild and can hang in the air because its density is about $\mathrm{g} / \mathrm{mL}$. However, the spike (S) proteins on the surface of the virus are around 90. This provides a technical advantage for the virus to bind to the receptor. Moreover, these spikes can be considered quite long, each spike being approximately 9 to $12 \mathrm{~nm}$ in length, and the appearance is similar to a "sunbeam crown." The latent period of patients with COVID-19 is 3.69 days, and the infection period is 3.48 days. Moreover, the ordinary incubation period of COVID-19 is 5.1 days and the symptomatic formation time is II.5 days. Depending on these values, a maximum duration of 12.5 days in 95 percentiles and a quarantine period of 14 days is sufficient. The basic number of reproduction (Ro) of COVID-19 is estimated to be 2.24-3.58 days (2). Although the primary route of transmission is through the respiratory tract, patients affected by COVID-19 also have viruses in the intestinal system, kidney, and sweat glands. Contrary to common knowledge, COVID-19 can also be thrown and smeared through feces, urine, and sweat (I, 2).

Based on the results of the current studies, it has been suggested that spike (S) protein, envelope protein, membrane protein, nucleocapsid protein, $3 \mathrm{CL}$ protease, papain-like protease, RNA polymerase, and helicase protein are potential targets for antiviral drugs. As of now, no licensed antiviral drug confirmed by the Food and Drug Administration (FDA) or the European Medicines Agency is available to treat COVID-19 patients. Moreover, the absence of approved vaccines 
and the absence of FDA-approved therapeutic agents against COVID-19 prevent the control of the outbreak and lead to the use of other treatment methods. Furthermore, the WHO reports confirmed that a "vaccine or specific pharmaceutical therapeutic for COVID-19" is not available as of now (2-4).

\section{Ozone and Hormesis}

Now let us take a closer look at the atomic structure of the ozone, which stimulates the body's antioxidant defense system, at least by triggering the oxidative stress (OS). Ozone is a naturally occurring gas produced from $\mathrm{O}_{2}$ atoms in the atmosphere. The $\mathrm{O}_{2}$ molecule consists of $2 \mathrm{O}_{2}$ atoms. These $\mathrm{O}_{2}$ molecules are separated into the atoms by energy discharge or ultraviolet (UV) light from the sun during lightning storms. Single oxygen atoms cannot endure alone without being regrouped into di-atomic oxygen molecules. In this recombination phase, some atoms will transform into loosely bound triatomic $\mathrm{O}_{3}$ (Figure I). This novel molecule is called ozone or $\mathrm{O}_{3}(3)$. In experiments conducted about a hundred years ago, water was shown to emit an electrical odor after electrolysis. The smell of this water is called "ozone," which means "odorant." In the gas phase, three oxygen atoms located in the ozone form an isosceles triangle with an angle of $1.26 \mathrm{~A}^{\circ}$. Ozone gas, discovered about a hundred years ago in the middle of the 19th century, is a gas made up of three oxygen atoms in a dynamically unstable structure due to the presence of mesomeric states. In fact, ozone has an even number of electrons in its outer orbit, meaning it has no unpaired molecules. As a result, although ozone is not a radical molecule, it is much more reactive than $\mathrm{O}_{2}$ and easily produces some ROS produced by $\mathrm{O}_{2}(2,4)$.

$\mathrm{O}_{3}$, which consists of $\mathrm{O}_{2}$ in the ozone layer in the upper layers of the atmosphere, performs an extremely important function for life on earth. The main function of ozone is to keep humans from the detrimental effects of the UV radiation of the sun. Ozone is contained in the atmosphere in concentrations perfectly compatible with life and is formed on the earth's surface in less than $20 \mu \mathrm{g} / \mathrm{m}^{3}$. In fact, ozone is a bidirectional gas (5).

The first effect of the ozone layer performs a vital task in blocking most of the carcinogenic UV radiation having the wavelengths of 100-280 nm from the electromagnetic waves spectrum emitted by the sun in the stratosphere, which is the upper part of the

\section{Main Points:}

- $\quad$ SARS-CoV-2 (COVID-19) is an RNA virus containing (S) spike proteins that contain abundant cysteine amino acids in its structure.

- No cure or vaccine for COVID-19 is available yet. Therefore, simple inexpensive adjuvant therapies are very important in COVID-19.

- Ozone, which has been safely involved in treatments for a long time with its triatomic $\mathrm{O} 3$ structure, can be used as an adjuvant treatment for COVID-19. Our first presentations in this field have attracted attention in the literature.

- Possible effectiveness of ozone on sulfhydryl groups and hormetic activity has been discussed in detail for the first time in the literature. atmosphere. However, the second effect may not be very useful. Unfortunately, increasing carbon dioxide with global warming can damage the ozone layer. As a result, the increased ozone concentration in the troposphere, which is the lowest layer of the atmosphere, that touches the ground and where gases are the most intense, can cause serious pulmonary injury and raised mortality in humans. Although this effect of the ozone appears to be harmful, empirical and clinical evidence for the medical use of ozone has been growing for nearly a century $(4,5)$.

Paracelsus, laying the foundations of toxicology, made a wellknown definition in the $16^{\text {th }}$ century. He worked on the development of modern toxicology, saying that "nothing is actually poison and everything is nontoxic and only the accurate dose distinguishes a poison from a drug." Low-dose exposure of the cell/organism to a toxic, chemical, or environmental factor accelerates the species' adaptation process. This mechanism, which exists in order for organisms to survive and proliferate against various stimuli/stresses around them and to respond adaptive$l y$, can be observed in the process of hormesis, an indispensable phenomenon in the evolutionary process $(5,6)$. During the biological evolution of the earth, the use of oxygen by metazoans allowed a fantastic biological diversity and growth in living things but also created a slow-acting "poison," which was oxygen. Moreover, oxygen can slowly poison biological organisms through oxidation by disrupting their molecular structure $(6,7)$.

Hormesis explains that the response to internal or external physiological and pathogenic stimuli/injuries that threaten the life of the cell or organism is not single-phase (linear) but biphasic or even multiple (multiphasic). The adaptive process and stability (homeostasis) in the organism are preserved or impaired depending on the balance (dose, severity, and frequency) of these physiological-pathological stimuli. Hormetic stimuli elicit adaptive epigenetic phenomena. Unfortunately, contemporary life requires us to live in millions of chemicals. Therefore, the dose-poison relationship has become more important today. The biphasic dose-response curve of the ozone is a common finding of experiments in the field of toxicology, but this low-

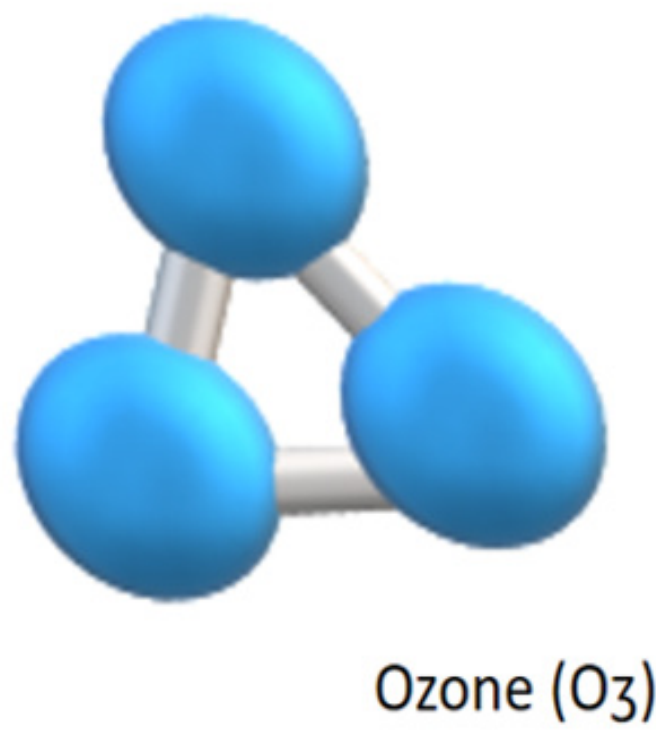

FIGURE I. Molecular structure of ozone 


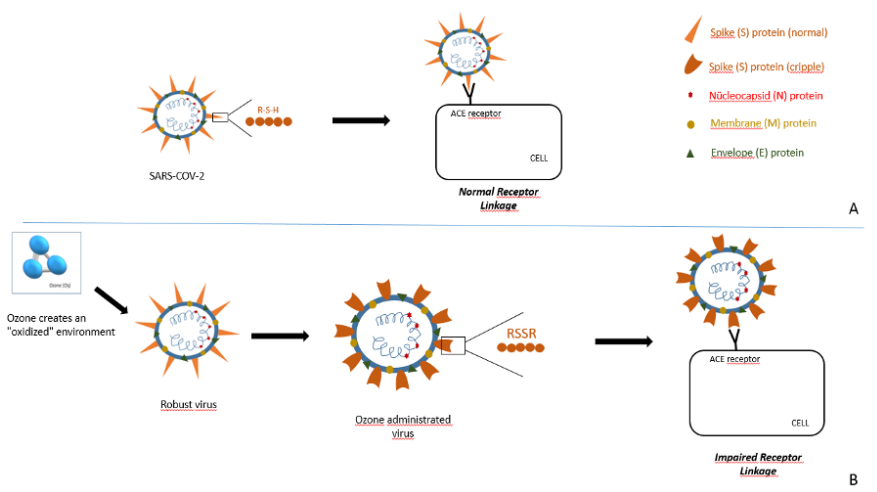

Figure 2. a, b. (a) Covid-19 and cell receptor linkage (b) The effect of ozone on the Covid-19's (S) protein and its results on the virüs receptor linkage

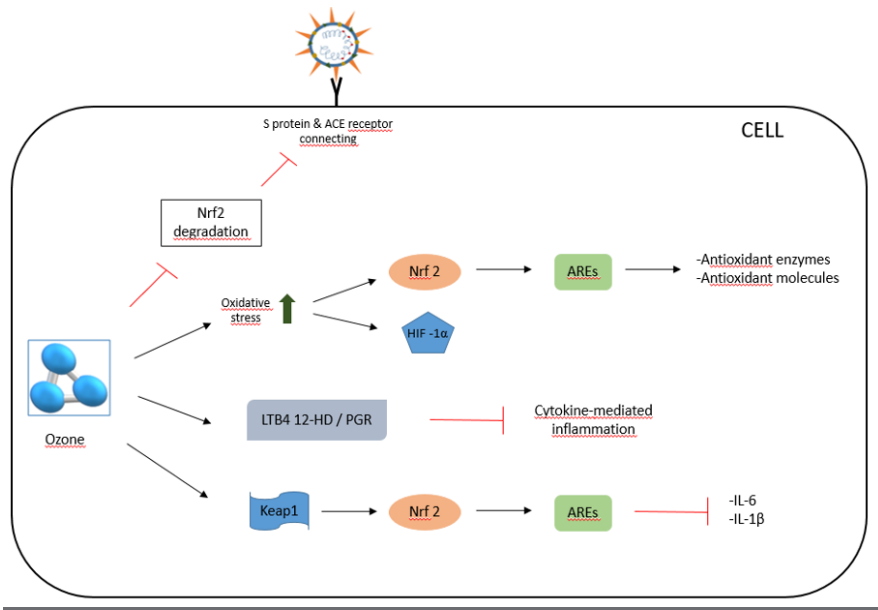

Figure 3. The effects of ozone in the cell

dose data is often overlooked, and the current appearance is that it is necessary to reduce toxin levels as much as possible. But in fact, in many cases, it has been found that these 'toxins' have important and beneficial effects, for example, at low doses of ozone. Moreover, many, but not all, drugs show hormone-dose behaviors $(3,6-9)$.

Despite this oxidation process, how is oxygen-dependent life possible? The answer to this is quite simple. We can say that the antioxidant system developed by living aerobic organisms, despite the presence of oxygen, has evolved over the past 2 billion years to counteract the destruction of biological life by oxygen. Indeed, the human antioxidant system has a difficult function in mitochondria to counteract the formation of a substantial amount of superoxide anions, such as approximately 3-5 g per day, and the sustained leaving of hydrogen peroxide $\left(\mathrm{H}_{2} \mathrm{O}_{2}\right)$ released by nicotinamide adenine dinucleotide phosphate (NADPH) oxidases found everywhere in the cells (7-9).

But during this task, the auxiliary of the antioxidant system is actually the oxidant agents created. Paradoxically, the appropriate dose definition and hormetic laws mentioned by Paracelsus come into play, and the signal message that is obligatory for life can be provided thanks to the physiological production of $\mathrm{H}_{2} \mathrm{O}_{2}$ in the cell. Indeed, the term "hormesis," which is very common today, can be defined as "the beneficial effect of display to a high dose of a harmful agent at a low dose," which is a double-sided effect. When we evaluate the behavioral activity of ozone, we can see a complete hormetic application. First of all, with the delivery of ozone in suitable conditions and doses to human blood, an OS occurs first. This is the first wave of the ozone effect. With the production of highly reactive messengers, a homeostatic change occurs in the person. An adaptive phenomenon, developed in the evolutionary process against this sudden OS occurring in the person, comes into play and the biochemical antioxidative reactions are induced at the cellular level. Stresses constitute an exceedingly helpful adaptation response represented by the revitalization of crucial defense mechanisms (9II). For example, until 2002, pharmacologically low ozone doses were thought to be stimulating and high doses were preventive. Let us make a simple analogy, for example, although a low antigen dose like a vaccine has been suggested to be preventive from diseases. The fact that ozone is almost immune-stimulating is not very suitable. Although ozone acts in a complex manner and, even at high doses, can be differently effective, this high dose may be accompanied by some side effects $(10,11)$.

\section{Ozone and Oxidation Potential}

As it turns out that, structurally, although ozone is not a radical species in itself, it can be thought that the possible toxic effects of ozone are caused by reactions from free radicals. In conditions of oxidation potential $\left(\mathrm{E}^{\circ}\right), \mathrm{O}_{3}(2.07 \mathrm{~V})$ is a strong oxidant next to fluorine $(3.06 \mathrm{~V})$ and hydroxyl radical $(2.80 \mathrm{~V})$. Other common oxidants have low power compared to $\mathrm{O}_{3}$ : hydrogen peroxide $(I .77 \vee)$, hypochlorous acid $(I .49 \vee$ ), and chlorine (I.36 $\checkmark)$. The electrical potential of ozone can be evident in the presence of water $(10, I I)$.

\section{$\mathrm{O}_{3}+2 \mathrm{e}-+2 \mathrm{H}^{+} \rightarrow \mathrm{H}_{2} \mathrm{O}+\mathrm{O}_{2}+2.075 \mathrm{~V}$}

Two types of different mechanisms can be proposed with ozone-induced radical-producing reactions: first is the classical strong radical type (hydroxyl radicals) which is formed and provides the oxidation of biomolecules, and the second is the mechanism that creates compounds, such as nonradical aldehydes (10-13).

Ozone is very unstable and has a half-life of about forty minutes at $20^{\circ} \mathrm{C}$ and is decomposed by an exothermic reaction. As is known, exothermic reactions are reaction types that can give energy out. In this case, ozone can release the released chemical energy to the organism. This complexity of the mechanism of action of ozone should always be considered in treatment. As a result, ozone can be considered as a pro-drug that produces biochemical messengers that can speed up electron transfer and general metabolism in the blood (9-13).

\section{COVID-19 and Ozone}

Ozone can be very useful in the treatment or prevention of viral infections. Usually, viruses are simple, free particles of macromolecules. Viruses, unlike bacteria, can only replicate in the infected host cell. In the years since the last two centuries, ozone has been applied in the treatment of many viral diseases. Ozone therapy was applied in addition to the standard treatment regimens in the first emerging SARS-CoV-I outbreak (2, 3, 9 , 13). The fact that ozone is an energy-rich molecule in addition to its unique physico-chemical and biological properties enabled beneficial results to be obtained in SARS-CoV-I patients $(9,10,13)$. 
Unfortunately, fewer scientific studies have shown the effect of ozone application on SARS-CoV-2. Studies showing that ozone application can be effective in SARS coronavirus disinfection are included in the literature. Since the structure of COVID-19 is very similar to that of SARS-CoV-I, it is safe to say that the same effects will work on COVID-19 as well $(3,8)$. As mentioned previously, the main mechanism of ozone gas on human biochemical pathways is oxidative pre-conditioning. This notion has been shown in both proteomics and genomics trials $(3,9)$.

With the simplest definition, ozone destroys the nucleic acids in the nucleus by damaging the viral RNA, starting with the lipid/ protein coating on their outer layers. At upper concentrations, ozone can demolish the capsid or outer protein shell of the viruses through oxidation. Numerous virus families (e.g., poliovirus I and 2; human rotavirus; Norwalk virus; parvoviruses; hepatitis $A, B$, and non- $A$, non-B) are viruses sensitive to the virucidal effects of ozone $(2,3, \mid 1-14)$. Most studies on the virucidal effects of ozone have focused on the tendency of ozone to break down lipid and protein molecules in multiple bond configuration areas. Indeed, viral DNA or RNA cannot survive when the virus' lipid envelope breaks down. So, enveloped viruses are usually more sensitive to physicochemical distress than naked virions (I3-I5). However, the effects of ozone on unsaturated lipids are one of the well-documented biochemical effects. Moreover, ozone is known to interact with proteins, carbohydrates, and nucleic acids. SARS-CoV-2 is an enveloped virus, like all other coronaviruses and many other respiratory viruses. When ozone comes into contact with the protein coat or shell of a virus particle, capsid, protein hydroxides, and protein hydroperoxides are formed. Fortunately, the capsid proteins of viruses have no protection against increased OS. The oxidation of phospholipids and lipoproteins, possibly caused by ozone therapy, may also damage the viral spike (S) protein and may disturb the COVID-19 viral replication cycle by disrupting the virus-host cell contact with peroxidation $(8,15)$.

\section{Sulfhydryl Groups of COVID-19 and Ozone}

Regarding protein-formed viral structures, ozone may be mainly interfering with sulfhydryl groups due to its remarkable affinity. Structural proteins of COVID-19 contain a large number of sulfhydryl (R-S-H) residues from the cysteine amino acid. The virus $\mathrm{S}-\mathrm{H}$ functional group is vital for COVID-19, meaning that thiol groups can be targeted in the fight against the virus. Therefore, many viral capsid glycoproteins must be in the form of reduced cysteine (SH) amino acids instead of oxidized cysteine amino acids (RSSR) to successfully penetrate host cells. For example, HIV and Ebola viruses also need reduced sulfhydryl (SH) groups, since the protection of the $\mathrm{SH}$ group is imperative for host receptor linkage $(2,3,8,15)$. Such viruses with such high virulence have cysteine-rich regions, including (S) protein and envelope proteins, similar to the structure of COVID-19. With these thiol groups, COVID-19 can often bind to the ACE enzyme receptor in the host cell, thereby contributing to viral fusion (Figure 2). Moreover, depending on the redox state, they can determine the ability to bind to this type of receptor as reduced thiol (SH) (open) or oxidized thiol (closed) (RSSR) $(2,3,15)$.

In fact, the three-dimensional protein structure in viruses, which is rich in cysteine amino acids, is highly vulnerable to oxidation, because oxidant agents, such as ozone, cripple and disrupt the protein structure in (S) proteins and can degenerate the three-dimensional structure of the virus. Similarly, ozone, which creates an "oxidized" environment in the blood, can help the defense system to directly neutralize the amino acid thiols involved in the structure of viruses in the blood and tissues. Moreover, the spike protein (S) of COVID-19 is very prone to oxidation because the structure of the spike protein has a high number of tryptophan amino acids after cysteine, and these amino acids can easily be oxidized (15).

In fact, ozone is made up of compounds called "ozonides." Ozonides are oxidant agents that can produce the fine-tuning effect of ozone other than its direct effect. Because ozonides are oxidant molecules on their own, they produce molecules of peroxides, peroxyls, alkenes, and alkanes. These molecules can oxidize cysteine and tryptophan amino acids and keep them in a "closed" position. Similarly, ozone also reacts easily with other amino acids containing methionine, tryptophan, and sulfur. Moreover, while cysteine-dependent proteins are inactivated by ozone administration, many enzymes in viral structures are inevitably affected, for example, ozone administration may inhibit the papain enzyme. Papain enzyme inhibition can reduce viral fusion/replication. In short, we can oxidize the three-dimensional structure of cysteine/methionine, tryptophan amino acid, and lipid in the critical membrane or protein structure by using the direct oxidant property of ozone and benefit from this critical redox fragility potential in fusion regions. The free thiol group of captopril blocks the catalytic $\mathrm{Zn}+{ }^{2}$ center of ACE-I. It is therefore desirable to use drugs with groups that can react covalently with COVID-19 essential proteins (I3-I5).

Similarly, even oxygen in the atmosphere can slowly destroy these sulfhydryl (thiol) groups in viruses through oxidation. The increase in heat can also strengthen the disrupting effect of oxygen on viruses at high atmospheric temperatures. Many viruses may gradually oxidize with atmospheric oxygen on external surfaces, such as COVID-19, and lose their ability to infect. Ozone can speed up the oxidation process made by atmospheric oxygen. For example, alcohol-based disinfectant solutions have a similar effect in preventing infections. Thiol ( $\mathrm{SH}$ ) bonds are much weaker than hydroxyl $(\mathrm{OH})$ bonds in alcohols, so alcohol-containing hand disinfectants can easily oxidize viruses through oxidation. But we should not forget that oxygen-dependent life has a strong antioxidant defense system against oxygen attack in the evolutionary process. With the help of these antioxidant mechanisms, ozone cannot harm the sulfur-containing amino acids in our cells $(15,16)$.

The main cellular mechanisms that protect amino acids against ozone oxidation in cells and blood are the oxidation of glutathione, oxidation of NADH/NADPH coenzymes, and other antioxidative systems. Simple RNA viruses like COVID-19, which have been living since the early ages of the world, need iron atoms for their catalytic activity in the absence of oxygen in the atmosphere, and since the atmosphere has no oxygen at that time, the antioxidant protection mechanisms do not occur. Therefore, sulfur-containing protein structures, such as (S) protein can easily be damaged through oxidation. This reaction can be very important for the antiviral effect to occur, because it causes the double bonds in the ozone protein structures to easily split through a reaction called ozonolysis (15-17). Likewise, acting 
ozone is a triatomic oxygen molecule, which reacts with bioorganic compounds holding double bonds, and the supplementation of three oxygen atoms to the unsaturated bond with the generation of ozonides can contribute to the fight against viral infections. Moreover, ozone can be widely used as an inexpensive, safe, and possibly effective agent in developing countries. Unfortunately, ozone therapy has not been widely applied as a treatment during the current COVID-19 outbreak. Italy and China are two examples of countries that have used ozone therapy in the treatment of COVID-19 patients. Much more work is needed for the development of the application of ozone therapy in future outbreaks. Ozone can be inexpensive, safe for use in combination with other treatments, and synergistically effective as an immunotherapy. Based on the data obtained, ozone therapy can be a useful method to control COVID-19 (16-18).

\section{Immunomodulation and COVID-19}

However, ozonides molecules are less reactive than the ozone' molecules, but their effects are resistant because they may activate several biochemical pathways and serve as biochemical signaling molecules that modulate the immune system. This immune modulatory effect can be helpful as a means of safely suppressing the "cytokine storm," including coronavirus (Figure 3). Our immune system, which is already developing in the evolutionary process, uses oxidant agents (e.g., hydrogen peroxide, superoxide, nitric oxide, hypochlorous acid) naturally for direct disinfectant purposes against microbes (18-20). It should be noted that the ozone gas exact has a double carbon bond and therefore reacts with unsaturated fatty acids present for the oxidative reaction, leading to the generation of peroxides following the hydrolytic breakdown of the poly-unsaturated lipid chains. Fortunately, COVID-19 is a very rich virus in terms of lipid presence $(I, 8)$. The lipid chains are thus broken down by the loss of their hydrophobic properties and converted into hydrophilic (i.e., water-collapsible components). Also, lipoperoxides, derived from the breaking of an ozonide chain, become water-soluble because they are short-chain lipid compounds. Due to this feature, when we wash our hands with soap, we can neutralize the virus (I-3). Ozone can likewise disrupt the viral structure by dissolving lipids by acting at the molecular level. In particular, COVID-19, like many other viral infections, can be more lethal in the elderly population. Ozone therapy can also be used to regulate the biochemical metabolic activities among the elderly (4). Generally, low-dose prophylactic applications of ozone therapy can stimulate slowed metabolic pathways in older individuals and can make older individuals more prepared for outbreaks through immune modulation using adjuvant therapy. Of course, we can think that ozone can be applied preferably in low-dose intervals in elderly individuals, whereas, especially if older individuals encounter COVID-19, keeping their metabolism awake may be possible with intermittent ozone sessions. Unfortunately, the cellular mechanisms that could explain the positive effects of intermittent blood ozone sessions need to be investigated further (|8-2|).

A small-scale ozone study against the COVID-19 outbreak can be an encouraging example. In this small study conducted in China (16), the clinical and laboratory results of patients receiving ozone using the major autohemotherapy (MAH) technique were evaluated. In short, MAH was reported to be very effective and serious COVID-19 patients were discharged faster (I6). The symptoms of these older patients, who were diagnosed with severe COVID-19, disappeared with MAH treatment, and their laboratory results and radiological findings were normalized $(4,16)$. Moreover, no side effects related to MAH have been reported in these elderly individuals with COVID-19 $(16,17)$. Patients who received $\mathrm{MAH}$ were found to be discharged in a shorter time compared to those who did not with the same age and findings. According to these preliminary study results and findings, the probability of ozone application as a treatment for COVID-I9 should be considered.

Currently, no therapeutic agent has yet been confirmed as an effective treatment for COVID-19. For this reason, publications supporting alternative treatment applications are very important for the containment of the COVID-19 pandemic. However, additional laboratory and clinical research are needed to established the effectiveness of ozone in treating COVID-19. Determining the optimal ozone dose and suitable treatment time may elicit the molecular effect. Moreover, many previous studies in the literature have reported that ozone administration is effective and safe in the treatment of some strong viral infections, such as HIV, hepatitis C, and Ebola. $(1,14,18,19)$.

\section{COVID-19 and Molecular Pathways of Ozone}

Perhaps the widespread clinical application of ozone in the COVID-19 outbreak may yield successful results. In monkey cells, the ability of the virus to be inactive with ozone in the laboratory is a sign of the existence of a basic molecular mechanism. Data on such molecules from many studies in the literature are promising. Ozone application may also reduce Nrf2 degradation and is a multi-effective molecule. This effect can reduce the activity of (S) protein and ACE2 and the effectiveness of SARS-CoV-I and COVID-19 receptors (I, 14-16).

Moreover, ozone can activate cellular antioxidant enzymes by affecting the transcription of antioxidant response elements (AREs) with the OS it temporarily creates. These enzymes include SOD, GPx, GST, CAT, HO-I, NADPH quinone (NQO-I), heat shock proteins (HSPs), and phase 2 enzymes involved in xenobiotic metabolism. This mechanism allows cells to stay awake by receiving a warning signal and fight viral infections $(22,23)$.

The stimulation of the Nrf2/AREs system with OS can stimulate the two intracellular antioxidant mechanisms, the glutathione system and thioredoxin system (10,23). The activation of the intracellular antioxidant system can be important, especially to prevent the replication of viral infections. For example, glutathione peroxidase (GPx), a selenoprotein, has been shown to inhibit HIV replication (23-25). In studies showing Nrf2/AREs interaction activated by light OS formed with ozone, it has been reported that ozone application can also increase the levels of strong antioxidant molecules, such as glutathione (GSH), carbon monoxide (CO), and serum bilirubin. Moreover, the effectiveness of ozone therapy can be clarified by the activation of other nuclear transcription factors, such as hypoxia inducible factor-la (HIF-la), which is also induced by moderate OS. These concepts have been widely acknowledged recently (22-24).

Leukotriene B4 (LTB4) is a lipid cell mediator synthesized from arachidonic acid and secreted by neutrophils, macrophages, and endothelial cells as a potent chemotactic agent in the 
blood. Ozone can have an anti-inflammatory effect in two different ways through enzymes. First, ozone can contribute to anti-inflammatory operation by stimulating the enzyme 12-hydroxyhydrogenase / 15-oxo-prostaglandin I3-reductase (LTB4 I2-H / PGR) involved in LTB4 metabolism. Second, ozone can contribute to the inhibition of cytokine mediated inflammation through LTB4 I2-HD / PGR enzyme induction (II-|4).

Ozone has the capability to release $\mathrm{O}_{2}$ when aqueous $\mathrm{pH}$ rises in the blood as well as protonic environments. The free iron $\mathrm{Fe}^{2}{ }^{2}$ load in the lungs may decrease with the increase in the amount of $\mathrm{O}_{3}$ in the atmosphere or the therapeutic application of ozone gas. On the contrary, an increase in storage iron, that is, the antioxidant molecule ferritin, can be observed. In this way, Fe+ ${ }^{2}-$ related cell death, that is, ferroptosis, can be reduced. In this study, the molecule that will reveal the ozone effect and determining factor is water (22-26). Without ozone $\mathrm{H}_{2} \mathrm{O}$, Criegee can react with unsaturated fatty acids to produce ozone. However, if the environment has plenty of water, $\mathrm{H}_{2} \mathrm{O}$, aldehydes, and hydrogen peroxide $\left(\mathrm{H}_{2} \mathrm{O}_{2}\right)$ are produced from ozone. Since $\mathrm{H}_{2} \mathrm{O}$ is abundant in the lungs, the main reaction with ozone will be the formation of aldehyde and $\mathrm{H}_{2} \mathrm{O}_{2}$ side-products. As a result, owing to ozonoids, ferritin synthesis, which has antioxidant activity, is induced, and thus the use of free iron and storage of free iron in the synthesis of ferritin inhibit the Fenton reaction $(9,15,21)$.

\section{$\mathrm{O}_{3}+\mathrm{H}_{2} \mathrm{O}_{2}+\mathrm{Fe}^{++}------\rightarrow \mathrm{OH}^{\circ}+\mathrm{OH}^{-}+\mathrm{Fe}^{+++}$}

COVID-19 infects the respiratory tract and causes mild-to-severe acute respiratory syndrome, resulting in the overproduction of pro-inflammatory cytokines, including interleukin IL-I and IL-6. The stimulation of host cell receptors by COVID-19's RNA can lead to the release of pro-IL-I $\beta$ cleavaged with caspase-I followed by the production of active mature IL-I $\beta$, a mediator of pneumonia and fibrosis. In severe cases of COVID-19, an inappropriate increase in cytokine levels, such as interleukin-6 (IL6), interleukin-IO (ILIO), and TNF- $\alpha$, can be observed. In some cases, these increased cytokine levels create a "cytokine storm" and cause significant damage to the lung tissue (23-26). For example, it should be expected that ozone application may suppress the cytokine production mechanism with NLRP3 inflammasome. Finally, it should be considered that inflammasomes, a cytoplasmic complex that mediates the proceeding and secretion of pro-inflammatory cytokines, are effective in the treatment of COVID-19. The activation of NLRP3 inflammation in monocytes and macrophages can be explained by the pathogenicity of SARS-CoV-I. This inflammasome complex response is the first immunologic process in a viral infection. The IL-I and IL-6 cytokines were secreted following the activation of inflammasomes, such as NLRP3, which regulate the cells in both the natural and adaptive immune complex and direct subsequent immune responses. Moreover, it can be concluded that ozone can also regulate cytoplasmic inflammasome activity (26-28).

Moreover, DNA repair mechanisms can be activated with ozone, and phagocytic activities can be increased in macrophages. In the severe form of COVID-19, the downregulation at the genetic level of IL-6 and other cytokines can be very valuable. Ozone can be applied as an adjuvant therapy to IL-6 blockers used in the treatment of COVID-19 to prevent cytokine storm. The effect of ozone on the nucleus in the cell results in the reduction of IL- 6 and IL-I $\beta$ after immune modulation is obtained in the
Keapl/Nrf2/AREs pathways. These data mean that the cytoprotective effect observed during ozone therapy may contribute to the suppression of the excess immune response caused by COVID-19 $(25,28)$. All of the discussed mechanisms imply that ozone administration during viral infection is a paradoxical pro-oxidant therapy that initiates an endogenous antioxidant response. All experimental results have shown that $\mathrm{O}_{3}$ in ex vivo or in vivo therapeutic dosages may activate Nrf2 while inhibiting the NF-kB pathway. The opposite is the NF-kB pathway; TNF- $\alpha$ activates the release of pro-inflammatory cytokines, such as IFN-y, ILI-y, IL6, and IL8, as well as the release of cyclooxygenase-2 (COX-2) and inducible nitric oxide synthase (iNOS). This effect occurs with pro-inflammatory genes $(1-3,28)$.

Studies on the genetic effects of ozone in the nucleus have been conducted. Studies have shown that ozone, known to accelerate wound healing, causes an important enhancement in the expression of various genes related to the wound healing process. In these studies, they found that ozone can reduce viral replication. Moreover, studies showing the genetic upregulation of immune system cells are proof that ozone can be much more effective than expected. Increased cell chemotaxis, leukocyte chemotaxis, and granulocyte chemotaxis have been demonstrated with ozone administration. The increased inflammation and excessive cytokine response in COVID-19 suggest that the ozone dose should be carefully adjusted at the hormetic level. Ozone, with its structural feature, can neutralize viruses by its direct oxidation $(1,3,15,16)$.

However, this mechanism may not be valid in vivo, because COVID-19 hides itself in the macrophages in the blood or in CD4+ lymphocytes and blood cells. Even worse, since the virus is in the cell in other organs, pneumocytes, hepatocytes, epithelium, and glial and neuronal cells, the direct antiviral effects of ozone become obscure, so the cell's powerful defensive antioxidant system unfortunately protects the viral integrity from itself. Ozone cannot achieve sufficient concentrations in the tissues because the plasma antioxidant capacity protects organ cells and intracellular viruses are inaccessible $(1,18,20)$.

Instead of increasing the dose, a low dose may be more appropriate for low-frequency hormetic activity. Thus, a prolonged ozone therapeutic treatment is sufficient for rebalancing the cellular redox condition, which is a basic process for adapting to OS and inhibiting viral replication. In fact, ozone gas permanently stimulates memory in immune cells, after being infused repeatedly during $\mathrm{MAH}$, lymphocytes and monocytes can migrate back into the lymphoid system and over time, the immune system's memory can be stimulated and activate other lymphoid cells $(13,20)$.

Consequently, at least ozone can be considered a possible adjuvant anti-inflammatory therapy for severe cases of COVID-19. Along with the accepted direct antiviral effects, ozone (partly due to intermediaries) has beneficial biochemical effects: (I) increase in NO; (2) improved erythrocyte rheology; (3) better hemoglobin functionality; (4) increase in 2,3-diphosphoglycerate; (5) improved mitochondrial oxidative phosphorylation; (6) temporary ROS increase; (7) NrF2/AREs pathway activation; (8) increase in ILIO; (9) increase in LTB4 I2-HD/PGR enzyme activity; (I0) decrease in pro-inflammatory cytokines and TNFa; (II) upregulation of GSH activity and hemeoxygenase pathway (24-28). 


\section{Ozone and Hypoxemia}

Ozone is a vasodilator, which can induce the production of prostacyclin. In infections that can cause severe hypoxic findings, such as COVID-19, it may cause injuries due to this feature. Ozone may be useful to avoid hypoxemia in viral infections, such as SARS-CoV-I and COVID-19, since $\mathrm{O}_{3}$ gas application can lead to the stimulation of 2,3-diphosphoglycerate, resulting in an increased amount of oxygen released into the tissues in erythrocytes. In this context, one of the main effects of ozone gas application is the acceleration of glycolysis, the only energy source of red erythrocytes (I, 3, 20). A basic condition to ensure the continuity of the glycolysis process is the continuous re-oxidation of NADPH, which occurs after ozone exposure. Moreover, ozone can increase ATP production, which will be needed in the organism's protection against infection, by activating the Krebs cycle by increasing the oxidative carboxylation of pyruvate. Studies on the genetic effects of ozone in the nucleus have been conducted. Because ozone can increase these two responses.

Still, a well-calibrated oxidant-stimulating ozone gas can modulate and infect different viral infections by stimulating the endogenous antioxidant system in infected patients. Moreover, the effectiveness of adjuvant ozone administration and correction of organ ischemia reperfusion should be expected as the anti-inflammatory effect of ozone (I, 28-30).

At the same time, the release of some HSP, such as HSP60, HSP70, and HSP90, which stimulate heme-oxygenase -I (HO-I), a protective enzyme, has been determined by ozone application. HSP and HO-I are robust activators of the innate immune system and can provoke the monocyte-macrophage system and activation of antigen-presenting cells. Also, ozone therapy increases oxygenation, especially in poorly oxygenated tissues. Ozone gas application stabilizes hepatic metabolism, which could improve hepatic protein synthesis in viral hepatic infections. Moreover, ozone may be beneficial in situations that impair liver enzymes, such as COVID-19. Ozone also activates the Nrf2 pathway, resulting in the induction of an antioxidative enzymatic system, such as $\mathrm{HO}-\mathrm{I}$. Ozon gas also suppresses NF$\kappa B$ activity by eliminating excess ROS that can cause NF-kB activation. It also binds directly to gene promoters by suppressing inflammatory cytokine gene expression (31, 32).

Ozone is ultimately an adjuvant therapy because the infected patient is treated with allopathic medication while undergoing adjuvant therapy. Although ozone has no direct effect on virus infection, it can provide a beneficial clinical effect with the help of the immune system, antioxidative system, and modulation of inflammatory cytokines. However, it should be noted that ozone can lead to an increase in toxic doses, NLRP3, and cytokine. Because ozone is a common oxidant gas in urban weather and ozone exposure can cause OS, it causes airway inflammation and increased respiratory morbidity. It shows that the rapid and wide spread of COVID-19 in northern Italy is highly associated with the measured air pollution of cities (33).

\section{CONCLUSION}

Systemic ozone application may be useful as a treatment method for COVID-19. Furthermore, large clinical studies are needed in the future to verify the use of ozone in complementary therapies for COVID-19.
Peer-review: Externally peer-reviewed.

Author contributions: Concept - N.Y.; Design - N.Y.; Supervision - E.E.; Resource - N.Y., C.Ö.; Materials - E.E., C.Ö.; Data Collection and/or Processing - N.Y.; Analysis and/or Interpretation - E.E.; Literature Search - E.E., C.Ö.; Writing - N.Y.; Critical Reviews N.Y.

Conflict of Interest: Authors have no conflicts of interest to declare.

Financial Disclosure: The authors declared that this study has received no financial support.

\section{REFERENCES}

I. Fernández-Cuadros ME, Albaladejo-Florín MJ, Peña-Lora D, Álava-Rabasa S, Pérez-Moro OS. Ozone (O3) and SARS-CoV-2: Physiological Bases and Their Therapeutic Possibilities According to COVID-19 Evolutionary Stage. SN Compr Clin Med 2020; 7: I-9. [Crossref]

2. Bar-On YM, Flamholz A, Phillips R, Milo R. SARS-CoV-2 (COVID-19) by the numbers. Elife 2020; 9: e57309. [Crossref]

3. Martínez-Sánchez G, Schwartz A, Donna VD. Potential Cytoprotective Activity of Ozone Therapy in SARS-CoV-2/COVID-19. Antioxidants (Basel) 2020; 9(5): 389. [Crossref]

4. Mueller A L, McNamara MS, Sinclair DA. Why does COVID-19 disproportionately affect older people? Aging (Albany NY) 2020; 12(I0): 9959-81. [Crossref]

5. Foladori P, Cutrupi F, Segata N, Manara S, Pinto F, Malpei, F, et al SARS-CoV-2 from faeces to wastewater treatment: What do we know? A review. Sci Total Environ 2020; 743: 140444. [Crossref]

6. Dhawan G, Kapoor R, Dhawan R, Singh R, Monga B, Giordano J, et al. Low dose radiation therapy as a potential life saving treatment for COVID-19-induced acute respiratory distress syndrome (ARDS). Radiother Oncol 2020; 147: 212-6. [Crossref]

7. Galiè M, Covi V, Tabaracci G, Malatesta M. The Role of Nrf2 in the Antioxidant Cellular Response to Medical Ozone Exposure. Int J Mol Sci 2019; 20(16): 4009. [Crossref]

8. Satarker S, Nampoothiri M. Structural Proteins in Severe Acute Respiratory Syndrome Coronavirus-2. Arch Med Res 2020; 5I(6): 48291. [Crossref]

9. Cavezzi A, Troiani E, Corrao S. COVID-19: hemoglobin, iron, and hypoxia beyond inflammation. A narrative review. Clin Pract 2020; I0(2): 127I. [Crossref]

10. Phaniendra A, Jestadi DB, Periyasamy L. Free radicals: properties, sources, targets, and their implication in various diseases. Indian $\mathrm{J}$ Clin Biochem 2015; 30(I): II-26. [Crossref]

II. Bocci VA, Zanardi I, Travagli V. Ozone acting on human blood yields a hormetic dose-response relationship. J Transl Med 20ll; 9: 66. [Crossref]

12. Quiros Roldan E, Biasiotto G, Magro P, Zanella I. The possible mechanisms of action of 4-aminoquinolines (chloroquine/hydroxychloroquine) against Sars-Cov-2 infection (COVID-19): A role for iron homeostasis? Pharmacol Res 2020; 158: 104904. [Crossref]

13. Martínez-Sánchez G, Schwartz A, Donna VD. Potential Cytoprotective Activity of Ozone Therapy in SARS-CoV-2/COVID-19. Antioxidants (Basel) 2020; 9(5): 389. [Crossref]

14. Valdenassi L, Franzini M, Ricevuti G, Rinaldi L, Galoforo AC, TireIli U. Potential mechanisms by which the oxygen-ozone (O2-O3) therapy could contribute to the treatment against the coronavirus COVID-19. Eur Rev Med Pharmacol Sci 2020; 24(8): 4059-6I.

15. Yilmaz N, Eren E, Kalayci Z, Saribek F, Oz C. How to cripple SARSCOV-2 virus with Ozone treatment Thiol groups in viruses and SARS-COV-2. 2020: Available from: https://www.researchgate. net/publication/340253197. 
16. Zheng Z, Dong M, Hu K. A preliminary evaluation on the efficacy of ozone therapy in the treatment of COVID-19. J Med Virol 2020; 92(II): 2348-50. [Crossref]

17. Mehraban F, Seyedarabi A, Seraj Z, Ahmadian S, Poursasan N, Rayati $\mathrm{S}$, et al. Molecular insights into the effect of ozone on human hemoglobin in autohemotherapy: Highlighting the importance of the presence of blood antioxidants during ozonation. Int J Biol Macromol 2018; 119: 1276-85. [Crossref]

18. Bocci VA, Zanardi I, Travagli V. Ozone acting on human blood yields a hormetic dose-response relationship. J Transl Med 20II; 9: 66. [Crossref]

19. Martínez-Sánchez G, Pérez-Davison G, Re L, Giuliani A. Ozone as u-shaped dose responses molecules (hormetins). Dose Response 20I0; 9(I): 32-49. [Crossref]

20. Bocci VA. Troposheric ozone toxicity vs. usefulness of ozone therapy. Arch Med Res 2007; 38(2): 265-7. [Crossref]

21. Yilmaz N, Eren E. Covid-19's passion for iron and fear of oxygen Perhapscovid-19 craves the atmospheric environment in ancient times. Retrieved from https://www.researchgate.net/publication/340584220. 2020.

22. Yilmaz N, Eren E. COVID-19 iron ferroptosis parafibrin. 2020: Available from: https://www.researchgate.net/publication/34I055648.

23. Smith NL, Wilson AL, Gandhi J, Vatsia S, Khan SA. Ozone therapy: An overview of pharmacodynamics, current research, and clinical utility. Med Gas Res 2017; 7(3): 212-9. [Crossref]

24. Di Mauro R, Cantarella G, Bernardini R, Di Rosa M, Barbagallo I, Distefano A, The Biochemical and Pharmacological Properties of Ozone: The Smell of Protection in Acute and Chronic Diseases. Int J Mol Sci 2019; 20(3): 634. [Crossref]
25. Elvis AM, Ekta JS. Ozone therapy: A clinical review. J Nat Sci Biol Med 20II; 2(I): 66-70. [Crossref]

26. Hernández A, Papadakos PJ, Torres A, González DA, Vives M, Ferrando $C$, et al. Two known therapies could be useful as adjuvant therapy in critical patients infected by COVID-19. Rev Esp Anestesiol Reanim 2020; 67(5): 245-52. [Crossref]

27. Yilmaz N, Eren, E. (2020). Covid-19 and Iron Gate The Role of Transferrin and Transferrin Receptor. 2020: Available from: https://www. researchgate.net/publication/340860987.

28. Galiè M, Covi $\bigvee$, Tabaracci G, Malatesta M. The Role of Nrf2 in the Antioxidant Cellular Response to Medical Ozone Exposure. Int J Mol Sci 2019; 20(16): 4009. [Crossref]

29. Juchniewicz H, Lubkowska A. Oxygen-Ozone (O2-O3) Therapy in Peripheral Arterial Disease (PAD): A Review Study. Ther Clin Risk Manag 2020; (16): 579-94. [Crossref]

30. Li F, Xu M, Wang $M$, Lei Wang, Wang $H$, Zhang $H$, et al. Roles of mitochondrial ROS and NLRP3 inflammasome in multiple ozone-induced lung inflammation and emphysema. Respir Res 2018; (19): 230. [Crossref]

31. Baver AK, Rondini EA, Hummel KA, Degraff LM, Walker C, Kleeberger SL. Identification of Candidate Genes Downstream of TLR4 Signaling after Ozone Exposure in Mice: A Role for Heat-Shock Protein 70. Environ Health Perspect 2011; II9(8): I09I-7. [Crossref]

32. Oakes JL, O'Connor BP, Warg LA, Burton R, Hock A, Loader J, et al. Ozone Enhances Pulmonary Innate Immune Response to a Toll-Like Receptor-2 Agonist. Am J Respir Cell Mol Biol 2013; 48(I): 27-34. [Crossref]

33. Zoran MA, Savastru RS, Savastru DM, Tautan MN. Assessing the relationship between ground levels of ozone $(\mathrm{O} 3)$ and nitrogen dioxide (NO2) with coronavirus (COVID-19) in Milan, Italy. Sci Total Environ 2020; 740: 140005. [Crossref] 